\title{
Artificial Pancreas: the Argentine experience
}

\author{
P. Colmegna ${ }^{1}$, F. Garelli², E. Fushimi ${ }^{2}$, M. Moscoso-Vásquez ${ }^{3}$, N. Rosales ${ }^{2}$, \\ D. García-Violini ${ }^{3}$, H. De Battista², and R. S. Sánchez-Peña ${ }^{3^{*}}$ \\ ${ }^{1}$ Center for Diabetes Technology, University of Virginia, USA and CONICET, Argentina \\ ${ }^{2}$ LEICI, Facultad de Ingeniería, UNLP, Buenos Aires, and CONICET, Argentina \\ ${ }^{3}$ Instituto Tecnológico de Buenos Aires and CONICET, Argentina \\ "Corresponding author. Email: rsanchez@itba.edu.ar.
}

\begin{abstract}
The objective of this work is to present a brief review on the international Artificial Pancreas project. In addition, the local project that led to the first Latin American clinical trials with an Artificial Pancreas will be described. These trials were performed in Buenos Aires during 2016 and 2017. The last trial used an algorithm developed in Argentina and defined as the ARG (Automatic Regulation of Glucose). This procedure and its in silico and clinical results will also be presented in this paper.
\end{abstract}

\section{Keywords:}

Diabetes type 1, closed-loop control, Artificial pancreas

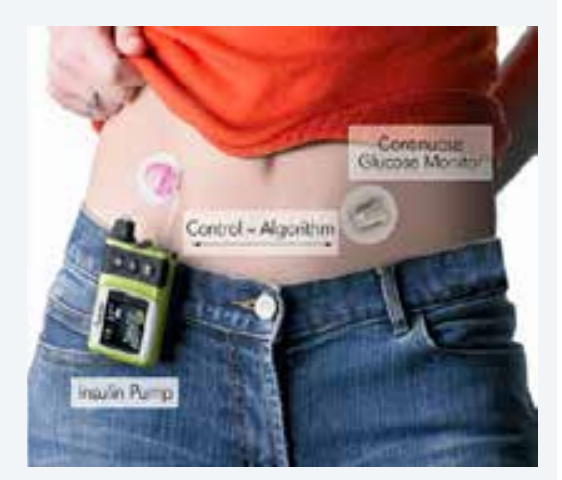

\section{Introduction}

Type 1 Diabetes Mellitus (T1DM) is a disease characterized by the inability to produce insulin, due to the destruction of the pancreatic $\beta$-cells. Insulin deficiency generates chronic hyperglycemia that can be related to several health complications, like the acceleration of Atherosclerosis [1]. In order to regulate their glucose levels, patients have to be continuously measuring their glycemia, and calculating how much insulin they need, making T1DM an extremely demanding disease. On the other hand, Insulin Intensive Treatment (IIT) is also associated with an increase risk of hypoglycemia [2].

An Artificial Pancreas (AP) is a system that automatically modulates patient's insulin infusion rate in order to maintain his/her blood glucose within safe limits. Although intravenous AP is possible [3], both measurement and infusion are, in general, performed subcutaneously via a Continuous Glucose Monitoring (CGM) sensor, and a Continuous Subcutaneous Insulin Infusion (CSII) pump, respectively. This represents a minimally invasive AP scheme that allows ambulatory use, but unfortunately, makes the control problem much harder. Amongst other difficulties, lag-times and errors in glucose measurement and insulin action, nonlinearities, large dynamic uncertainties and technical difficulties (sensor dropouts and insulin set failure) have to be coped with (see [4] and [5] for a complete review of the challenges in the development of an AP system). It is worth remarking that even rapid-acting insulin introduces a significant delay that affects the performance of a glucose controller [5]. Actually, this is the main limitation for AP systems, considering that according to pharmacodynamics profiles the peak of insulin action occurs about $70 \mathrm{~min}$ after infusion [6].

The AP development has been accelerated by the use of elaborated simulators, such as the UVa/Padova metabolic simulator which was accepted by the US Food and Drug Administration (FDA) in lieu of animal trials ( [7,8]. Recently, clinical trials were performed in different countries of the EU, USA, Israel and Australia [9-12]. The great majority of the control algorithms that have been clinically tested are based on Proportional-Integral-Derivative (PID), Model Predictive Control (MPC) or fuzzy logic controllers. Generally, they are hybrid (semi-automatic) control loops, where the controller action is complemented with premeal insulin boluses in both the single-hormone [13-17] and the dual-hormone [18,19] AP. Although the injection of an open-loop bolus based on the carbohydrate intake facilitates the reduction of postprandial glucose values [20], inaccurate carbohydrate counting is frequent [21]. In [19] meal announcement is not required, but it is suggested in order to trigger a meal-priming bolus based on a meal size classification akin to the proposal of [22,23].

Studies involving fully closed-loop AP systems can be found in [24, 25] and more recently in [26-29]. Despite 
promising results, there is still a strong compromise between the aggressiveness of the control action and the postprandial glucose excursion. This compromise exists even when meals can be anticipated based on a probabilistic approach like the one presented in [30]. If the controller is not aggressive enough to a meal perturbation, then prolonged hyperglycemia may occur $[20,26]$. On the other hand, if the controller is too aggressive, there is a higher risk of insulin overdosing, and consequently, postprandial hypoglycemia [28]. The latter is partially because the effect of the meal on the CGM signal is not immediate, and therefore, the insulin response generated by the controller to cope with the meal is delayed several minutes. It should also be considered that in the standard open-loop basal-bolus treatment, a unique insulin bolus is applied at meal times. Instead, in a feedback control scheme, multiple insulin boluses are generated in response to the change in the CGM signal. Furthermore, because the counter-regulatory response in people with T1DM is often compromised, the response of an AP control algorithm should be less aggressive than the $\beta$-cell's secretory response [5]. As a consequence, fully closed-loop systems have an increased risk of initial hyperglycemia and late hypoglycemia during meals in comparison with semi-automated hybrid strategies. In [29], this problem is reduced, because the insulin bolus to cover the meal is not generated by the multivariable adaptive controller per se, but by an additional module that infuses an insulin bolus when a meal is detected. A very recent set of articles in this area can be found in [31].

In this paper, relatively unexplored control techniques in the field are proposed to address the glucose control paradigm, and take a step forward towards a fully automatic control loop. In particular, a couple of Linear Quadratic Gaussian (LQG) controllers are employed as main feedback controllers in combination with a sliding-mode safety layer to include Insulin on Board (IOB) constraints. Both LQG controllers are arranged into a switched structure to cope with the trade-off between prandial and fasting periods by triggering the controller into an aggressive mode during meals. The combination of the switched LQG controller with the safety mechanism allows compensating for delays associated with subcutaneous insulin infusion. When the aggressive mode is triggered, an insulin spike is generated. This mimics the first-phase insulin secretion of the $\beta$-cell response [5]. On the other hand, the purpose of the safety layer is to reduce the insulin infusion commanded by the switched LQG controller when a predefined IOB limit is going to be violated. This latter characteristic can be associated with the suppression of the $\beta$-cell in proportion to plasma insulin levels [5]. In this way, an initial "under-damped" insulin response can be generated to compensate for insulin delays, without increasing the risk of postprandial hypoglycemia. It is worth remarking that here it is the first time the safety layer is employed to adapt a closed-loop control without premeal insulin boluses.

The proposed control structure also intends to simplify both controller tuning and implementation. This facilitated its in vivo validation in a clinical trial, where it was tested on five T1DM adults during 36 hours without carbohydrate counting. This was the second phase of the first AP clinical trial campaign in Latin America. In the first phase a hybrid controller was tested in the same site and by the same team [32].

\section{From The Conventional Therapy to Fully Automatic Control}

As it was previously mentioned, patients with T1DM are insulin dependent. This means that, according to the conventional therapy, they should monitor their glucose concentration levels and administer insulin injections every day for the rest of their lives. This makes T1DM a highly demanding disease for both the patients and their families. For example, the patient not only has to maintain a basal insulin delivery to stabilize fasting glucose levels, but also has to count the amount of carbohydrates present in every meal before eating in order to calculate how much insulin is necessary to counteract its effect. Sadly, this calculation is far from being exact in real life, which is why the patient is constantly exposed to hyperglycemia (in the case of an underestimation of carbohydrates) and hypoglycemia events (in the case of overestimation of carbohydrates). Also, there exists a risk of hypo and hyperglycemia due to the effects of stress, physical activity and other multiple situations related to every day life that end up having an impact on the glycemic levels of the patient, and therefore, in his/her quality of life. This is why automatic regulation of glycemia in T1DM is a issue that dates to the beginnings of the 1960's. At first, the intravenous route was considered for both insulin infusion and glucose monitoring. Afterwards, alternative routes were analyzed, but the biggest breakthrough was in the 1990's with the appearance of the continuous glucose monitor (CGM). This allowed to go from having a few measurements a day to having them every 5 minutes or less through a minimally invasive procedure. Fig. 1 shows a diagram of this monitoring system. Its main disadvantage is that there exists a delay between what is being measured in the interstitial space and the actual plasma glucose levels.

Regarding insulin infusion, the first continuous subcutaneous insulin infusion (CSII) pumps emerged in the mid 1970's. Even though the implantable pumps in the peritoneal cavity represent a more suitable alternative from the physiological point of view, the subcutaneous pumps, as they are less expensive and invasive, prevailed alongside CGMs as the main elements for an AP. Nevertheless, what is known in the scientific community as an AP needs to have, apart from the CGM and the CSII pump, an element to close the loop. This element is the control algorithm that is in charge of calculating the adequate amount of insulin to be infused according to the CGM readings (see Fig. 2). Calculating the adequate insulin dose is not an easy task. Some of the biggest challenges that the control algorithm must face are:

- The subcutaneous route introduces a delay between the CGM measurements and the actual plasma glucose levels. Additionally, the measurements usually have significant error, which is why CGMs require daily calibrations. 


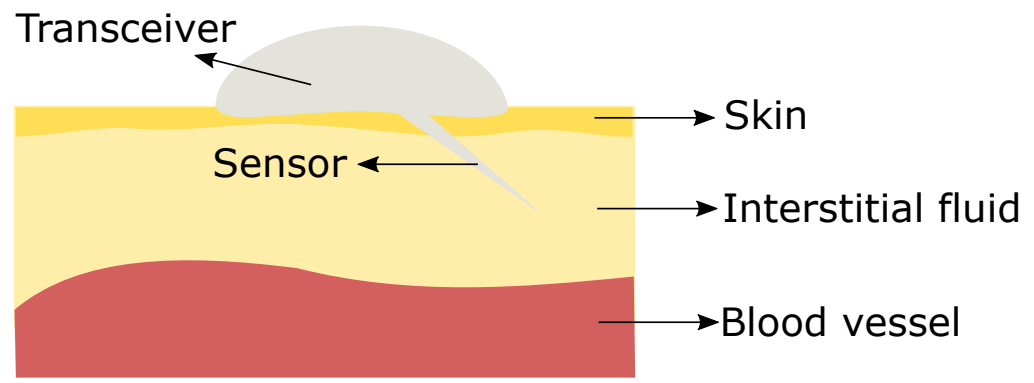

Figure 1. Continuous glucose measurement in the interstitial space.

- Like subcutaneous measurements, there exists a delay of several minutes associated to the absorption of the insulin that is infused at a subcutaneous level. In fact, the peak in the insulin action occurs approximately 1 hour after it has been infused, and its effect prevails for several hours. This means that the decision that is made every instant regarding how much insulin to administer, has prolonged consequences in time. An associated effect is the accumulation of active insulin, or what is known as Insulin On Board (IOB). In consequence, not taking into account past infusions might lead to insulin-induced hypoglycemia due to insulin stacking.

- The response to the same insulin dose varies from patient to patient (inter-patient variability).

- The same patient might respond differently to the same dose of insulin in different occasions (intra-patient variability).

A fundamental aspect to increase the celerity in the AP development was the progress of computational models of the insulin-glucose dynamics. Generally, the design of a control algorithm is based on a mathematical model of the system to be controlled. This is why numerous simulation models describing T1DM have been reported. These models have allowed not only to rapidly progress in the design of different controllers, but also to perform in silico tests previous to in vivo trials with humans.

\section{ARG algorithm}

The closed-loop glycemic regulation system with the ARG algorithm for a given \#j subject is illustrated in Fig. 3. It can be seen in the figure that the algorithm has two main components:

- a switched Linear Quadratic Gaussian (LQG) regulator; and

- a safety layer called SAFE (Safety Auxiliary Feedback Element)

In a first instance and with an introductory purpose, the interaction between these two components will be discussed. Subsequently, each element will be explained with detail.

As it is usual in a closed-loop system, there is a reference signal $r$, which in this particular case is the desired glucose concentration at fasting state. The difference between the desired glucose concentration and the one measured by the CGM is defined as the error signal $e$, which is the input to the ARG algorithm. A control signal $u_{\mathscr{C}}$ is generated by the algorithm,

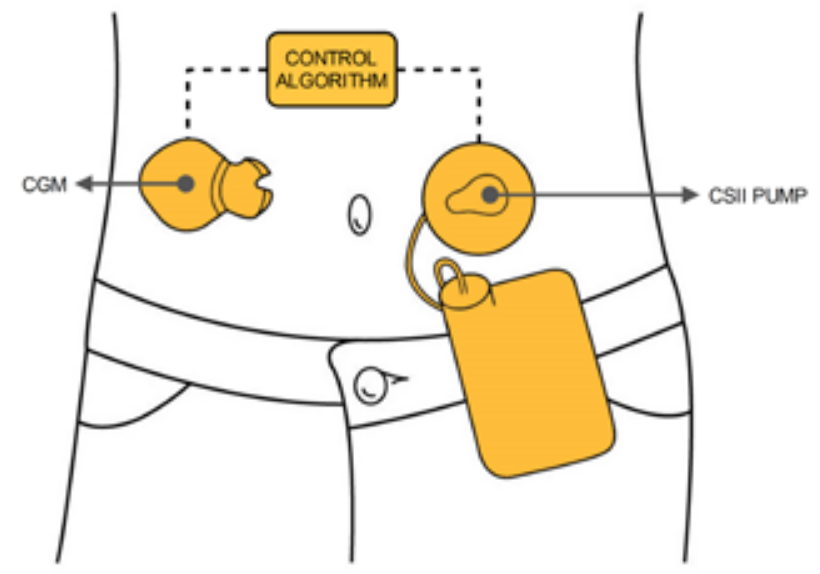

Figure 2. AP diagram. 


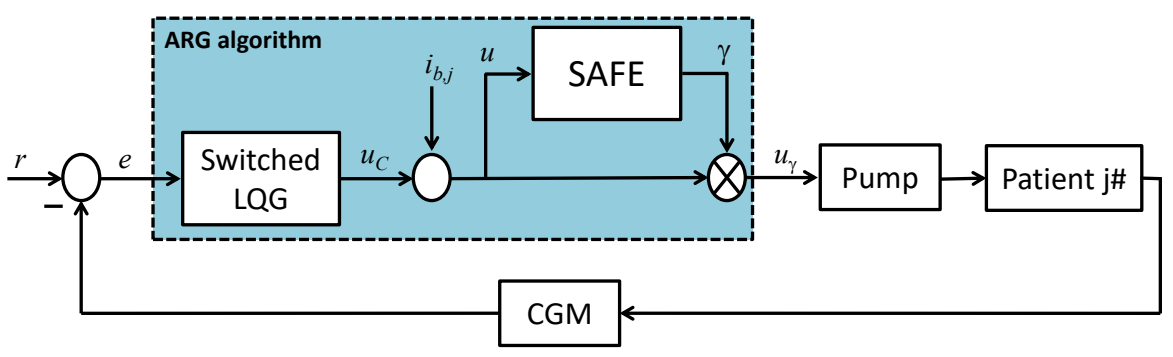

Figure 3. Closed-loop system with the ARG algorithm, where $i_{b, j}$ is the patient-specific basal rate, and $r$ is the reference glucose concentration.

which corresponds to the switched LQG output. Since there is not integral action in order to avoid insulin stacking, the basal infusion of the patient $i_{b, j}$ is added to the $u_{\mathscr{C}}$, thus generating the signal $u$. If the SAFE block is not present, the signal $u$ would command the patient's insulin pump. However, the presence of the SAFE layer, where $u$ is its input and $\gamma$ is the output, modulates the proposed infusion by the switched LQG controller in order to avoid an insulin overdose. In this way, the control action that commands the insulin pump is $u_{\gamma}$, consisting in the infusion proposed by the switched LQG regulator multiplied by the output of the SAFE block $\gamma$.

For a more detailed description of the algorithm, the reader is referred to [33].

\subsection{Switched LQG regulator}

The switched LQG regulator is constituted by two LQG regulators: on one hand, by default $\mathscr{K}_{1}$ makes smooth corrections on the basal insulin infusion; and on the other $\mathscr{K}_{2}$ is conceived for fast and aggressive corrections. The commutation to the $\mathscr{K}_{2}$ controller occurs at meal time and it can be both manual or automatic. If the commutation is produced manually, the patient must announce the meal time by means of a button, for example. If it is in an automatic manner, there must be a detection mechanism that allows inferring that the patient has eaten, for example, by means of the CGM signal. The problem that arises with this mechanism is the strong compromise between a fast detection and an immunity to the large CGM noise, which is of great importance in postprandial glycemic control. Because of this reason, the authors have chosen a manual commutation for the first clinical trials, although obtaining good in-silico results of the automatic mechanism [34-37].

It should be noted that, although the patient must announce the moment of the meal, he does not have to count the amount of carbohydrates that is about to ingest, translating thus in a lower burden in their daily tasks. Once the meal has been announced, the algorithm does not commute immediately to the aggressive controller $\mathscr{K}_{2}$, but switches to a listening mode in which the CGM signal trend is processed. When a sustained rise of the measurements is detected, the commutation to $\mathscr{K}_{2}$ is produced with the purpose of generating a control action similar to the standard insulin bolus treatment. The commutation from $\mathscr{K}_{2}$ back to $\mathscr{K}_{1}$ is produced in an automatic manner after 1 hour of operation of the aggressive controller, but other strategies involving the SAFE layer could be exploited.

A fundamental element when designing controllers are the control oriented models. On one side, models for simulation, as in the case of the UVA/Padova simulator, are developed in order to offer a response as real as possible, but are often complex, nonlinear and high order. On the other side, control theory generally applies simpler models in order to obtain low-order controllers and numerically better conditioned problems. To this end, assumptions over the simulation models are done, thus obtaining control-relevant low-order models for controller design. The drawback that adds to the obtaining of control oriented models in T1DM is that, what is commonly known as the plant in control engineering, are people in the case of T1DM. Thus, the usual identification methods applied to other types of systems, such as an engine, can not be extrapolated here for obvious reasons. That is why usually in this area, mean models are proposed as a first approach for describing insulin-glucose dynamics. Nevertheless, as mentioned above, there is a huge inter-patient variability which makes impossible the task of designing a single controller for all patients. Then, how can control-oriented models be adjusted? The model can be customized, in most cases, from the patient's clinical data, such as weight, Total Daily Insulin (TDI), the insulin to carbohydrate ratio (CR), among others. That is to say, that the control-oriented models are tuned taking into account the parameters that the patients use daily for their own glucose control.

The ARG algorithm switched LQG regulator is based on a Linear Time Invariant (LTI) version of the Linear Parameter Varying (LPV) control-oriented model previously developed by two of the authors in $[37,38]$. Without going into greater detail, in [37] a low-order LTI model is proposed, similar to the one in [39], where the input corresponds to the subcutaneous 

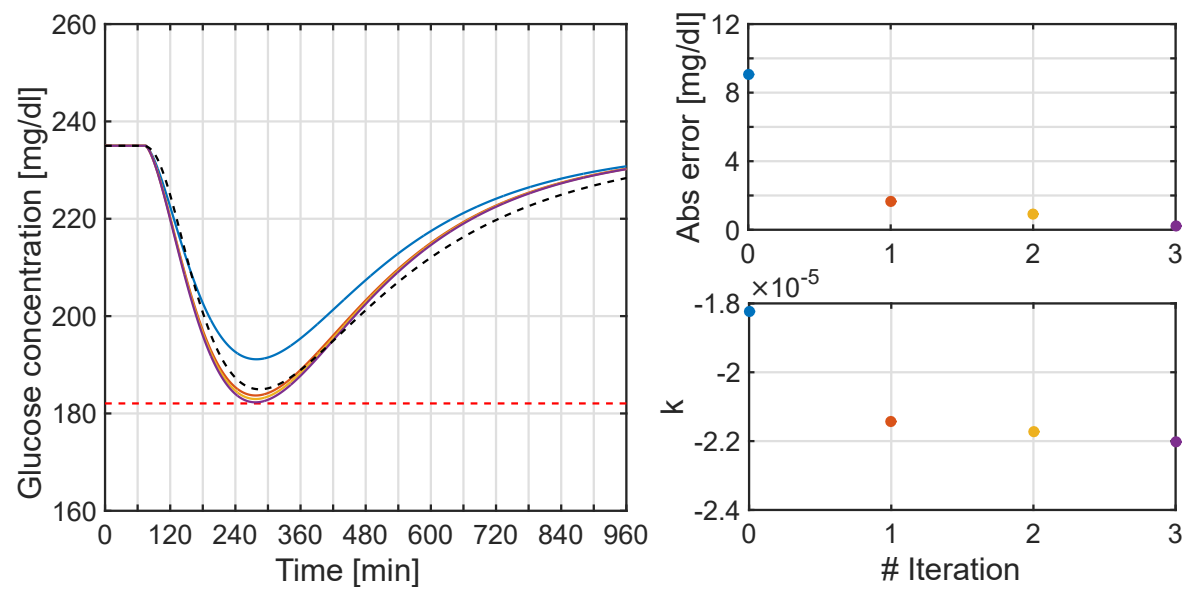

Figure 4. Parameter $k$ adjustment process for an adult from the UVa/Padova simulator database.Left: Glucose excursion before $1 \mathrm{U}$ of insulin for the average LPV model (light-blue solid-line) and nonlinear model (black dashed-line); minimum reachable glucose concentration given by the 1800 rule (red dashed-line). Upper-right: Absolut error between the obtained and the desired glucose drop. Lower-right: Evolution of the parameter $k$.

insulin infusion (in $\mathrm{pmol} / \mathrm{min}$ ) and the output is the glucose concentration deviation (in $\mathrm{mg} / \mathrm{dl}$ ):

$G(s)=k \frac{s+z}{\left(s+p_{1}\right)\left(s+p_{2}\right)\left(s+p_{3}\right)} \mathrm{e}^{-15 s}$.

Afterwards, a time varying behavior of the insulin-glucose system is described through the construction of an LPV average model, by making the parameter $p_{1}$ vary with respect to glucose concentration $g$ and keeping the rest parameters fixed as follows: $z=0.1501, p_{2}=0.0138$ and $p_{3}=0.0143$. The gain parameter $k$ is also time invariant, but is adjusted for each particular patient, exploding the insulin sensitivity factor of the standard therapy, known as the 1800 rule (may vary between authors). Given a patient $\# j$, the gain is computed as $1800 / \mathrm{TDI}_{j}$, where $\operatorname{TDI}_{j}$ the total daily insulin of the patient, and represents the glucose drop in $\mathrm{mg} / \mathrm{dl}$ before an infusion of $1 \mathrm{U}$ of rapid acting insulin. Since insulin sensitivity depends on the glucose concentration, among other factors, the 1800 rule is verified in average starting from an initial glucose concentration of $235 \mathrm{mg} / \mathrm{dl}$ [37]. Therefore, the adjustment process for obtaining the customized value of $k$, namely $k_{j}$, is that when the model is excited with $1 \mathrm{U}$ of insulin at $235 \mathrm{mg} / \mathrm{dl}$, the result matches the 1800 rule. The larger the glucose drop, the more sensitive the patient is to insulin, thus, greater is the absolute value of $k_{j}$. An illustrative example of the iterative process for obtaining the parameter $k_{j}$ is depicted in Fig. 4 (this could also be done analytically). This process consists in adjusting the value of $k_{j}$ by means of a Proportional-Integral (PI) discrete controller until the relative error between the glucose drop by the LPV model and the 1800 rule be less than a small enough value. In summary, a low-order average LPV model is proposed first, which is then personalized through a parameter easily accessible and known by the patient. This LPV model has a better fit with the UVa/Padova simulator in terms of the RMSE and also with the $v$-gap metric. The latter indicates a potentially better closed-loop performance when designing a controller based on this LPV model.

Although previously designed LPV controllers had successful results, the original idea behind the ARG algorithm was that it would have to have the lowest possible computational cost, in view of its verification in clinical trials. That is why LQG regulators were selected in order to allow adjusting the aggressiveness in an easy and intuitive way. Hence, for each patient $\# j$ two LQG regulators are designed: $\mathscr{K}_{i, j}$ with $i \in \mathscr{I}=\{1,2\}$, based in the following model:

$G_{j}(s)=k_{j} \frac{s+z}{\left(s+p_{1}^{*}\right)\left(s+p_{2}\right)\left(s+p_{3}\right)} \mathrm{e}^{-15 s}$,

which is the LTI version of the custom LPV model with $p_{1}^{*}=p_{1}(120)$. In this case, $p_{1}$ is set for a concentration of 120 $\mathrm{mg} / \mathrm{dl}$, which is the average basal glucose concentration determined in the UVa/Padova simulator.

Since the CGM sensor does not send measures continuously, but every $5 \mathrm{~min}$, the continuous model $G_{j}(s)$ is discretized by means of a zero-order hold, being expressed by the following realization:

$$
\begin{aligned}
x(k+1) & =A_{j} x(k)+B_{j} u_{\Delta}(k) \\
y_{\Delta}(k) & =C_{j} x(k)
\end{aligned}
$$

with $u_{\Delta}(k)=u(k)-i_{b, j}$, and $y_{\Delta}(k)=y(k)-120 \mathrm{mg} / \mathrm{dl}$. Given this realization, a state feedback control is proposed

$u_{\Delta}(k)=-K_{i, j} x(k)$ 


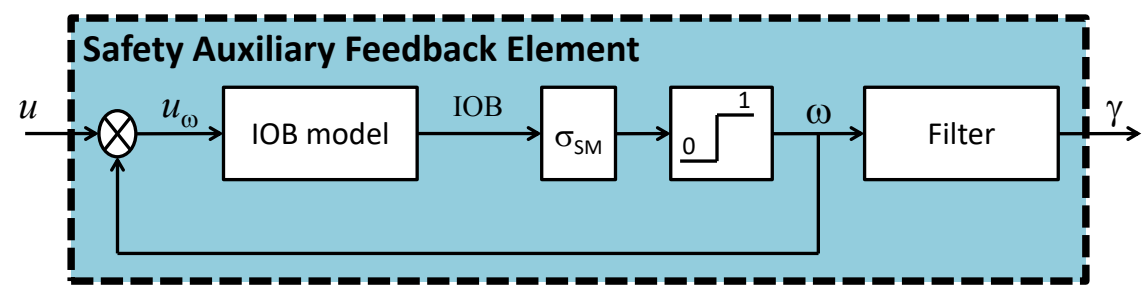

Figure 5. SAFE layer block diagram.

which minimizes the following functional cost

$J_{i}\left(u_{\Delta}, y_{\Delta}\right)=\sum_{k=0}^{\infty}\left(R_{i} u_{\Delta}^{2}+Q y_{\Delta}^{2}\right)$

where $R_{1}=1, R_{2}=0.5$, and $Q=5 \times 10^{3}$. The parameter $R_{2}$ is defined smaller than $R_{1}$ in order to $\mathscr{K}_{2, j}(z)$ be more aggressive than $\mathscr{K}_{1, j}(z)$. In addition, the states are estimated with a Kalman filter in the form of:

$\hat{x}(k+1 \mid k)=A_{j} \hat{x}(k \mid k-1)+B_{j} u_{\Delta}(k)+L_{i, j}\left[y_{\Delta}(k)-C_{j} \hat{x}(k \mid k-1)\right]$

where $L_{i, j}$ is obtained assuming that the process noise $w(k)$ and the measurement noise $v(k)$ correspond to white noise, satisfying

$E\left[w(k) w(k)^{T}\right]=W_{i}, \quad E\left[v(k) v(k)^{T}\right]=V_{i}$

with $W_{1}=V_{1}=W_{2}=3$, and $V_{2}=45 \times 10^{-4}$. Here, $V_{2}$ is defined smaller than $V_{1}$ in order to $\mathscr{K}_{2, j}(z)$ have a faster response than $\mathscr{K}_{1, j}(z)$.

Both controllers $\mathscr{K}_{1, j}(z)$ and $\mathscr{K}_{2, j}(z)$ have an observer structure with state feedback and constitute the switched controller. The stability of this switching can be proved using the results detailed in [40]. The details of this result are beyond the scope of this paper, but the basic idea is to express the switched controller in such a way that it can arbitrarily switch between both LQG controllers without the need to reset the states and in a very simple way (only a part is switched from the $C$ matrix of the controller).

\subsection{SAFE layer}

The SAFE layer, detailed in Fig. 5, is based on the sliding mode reference conditioning technique, developed by one of the authors in his PhD. Thesis [41]. This technique, designed in general for control of constrained systems, was first applied in the T1DM problem in [42], and then successfully tested on clinical trials in Spain. Its main objective is to modulate the gain of the controller to prevent Insulin On Board (IOB) from stacking by imposing a constraint $\overline{\mathrm{IOB}}_{j}(t)$, thus reducing the risk of hypoglycemia in late postprandial periods.

The original SAFE layer was simplified with the objective of programming it in the hardware provided for the tests. The core element of any sliding mode control is the switching logic, which in this case is:

$w(t)= \begin{cases}1 & \text { if } \sigma_{\mathrm{SM}}(t)>0 \\ 0 & \text { else }\end{cases}$

with $\sigma_{\mathrm{SM}}(t)$ being the sliding function, defined simply as the difference between the actual IOB level and the imposed limit

$$
\sigma_{\mathrm{SM}}(t)=\overline{\mathrm{IOB}}_{j}(t)-\mathrm{IOB}(t)
$$

The limit $\overline{\mathrm{IOB}}_{j}(t)$ is considered piecewise constant a-priori, as it is explained later.

Because IOB cannot be measured in real time, it must be estimated. To this effect, the model presented in [43] is considered, which has the advantage that it can be customized based on a single clinical parameter:

$$
\begin{aligned}
\dot{I}_{s c 1}(t) & =-K_{\mathrm{DIA}} I_{s c 1}(t)+u_{w}(t) \\
\dot{I}_{s c 2}(t) & =K_{\mathrm{DIA}}\left[I_{s c 1}(t)-I_{s c 2}(t)\right] \\
\mathrm{IOB}(t) & =I_{s c 1}(t)+I_{s c 2}(t) .
\end{aligned}
$$

where $I_{s c 1}$ and $I_{s c 2}$ are, respectively, the amount of nonmonomeric and monomeric insulin in the subcutaneous space, $u_{w}$ is the exogenous insulin infusion rate in $[\mathrm{pmol} / \mathrm{min} / \mathrm{kg}]$, and $K_{\mathrm{DIA}}\left[\mathrm{min}^{-1}\right]$ is a constant that can be tuned in order 
to replicate each patient's duration of insulin action (DIA) [44]. It should be noted that DIA is a clinical parameter adjusted in actual insulin pumps. As a starting point, an average DIA of 5 hours was selected, leading to a $K_{\text {DIA }}$ fixed at $16.3 \times 10^{-3}\left[\mathrm{~min}^{-1}\right][45]$.

When the $\overline{\mathrm{IOB}}_{j}(t)$ limit is reached by the IOB estimation, a sliding regime is established over the surface $\sigma_{\mathrm{SM}}(t)=0$. During this mode, from (8), the signal $w(t)$ switched at high frequency between 0 and 1 , in order to fulfill the imposed restriction and force the system (10) to remain within the invariant set

$\Sigma=\left\{x(t) \mid \sigma_{\mathrm{SM}}(t) \geq 0\right\}$

where $x(t) \in \mathbb{R}^{2}$ are the states of (10). The switching signal $w(t)$ is smoothed by a first order filter (or averaged between infusion intervals), given place to $\gamma(t)$, which is the factor that modulates the signal commanding the pump.

Observation: It is easy to prove that the derivative of the switching function $\sigma_{\mathrm{SM}}(t)$ depends on the control action $u_{w}(t)$, and therefore of the discontinuous action $w(t)$, which is a necessary condition for establishing the sliding mode, known as transversality condition.

Like the main controller, the SAFE layer is implemented in a discrete way, obtained from (10) as:

$$
\begin{aligned}
x(k+1) & =\left[\begin{array}{cc}
1-K_{\mathrm{DIA}} T_{r} & 0 \\
K_{\mathrm{DIA}} T_{r} & 1-K_{\mathrm{DIA}} T_{r}
\end{array}\right] x(k)+\left[\begin{array}{l}
1 \\
0
\end{array}\right] u_{w}(k) \\
\mathrm{IOB}(k) & =\left[\begin{array}{ll}
1 & 1
\end{array}\right] x(k)
\end{aligned}
$$

with $T_{r}=0.1$ being min the sample time. It should be noticed that $T_{r}$ is smaller than $T_{s}=5$ min since the SAFE algorithm is programmed entirely in software, thus, the switching frequency is only limited by the speed of the pump microprocessor.

While there may be different criteria to define the IOB limit, from the conducted clinical test it was defined from a classification of the meal size, as follows:

- Small meal $<35 \mathrm{gCHO} . \overline{\mathrm{IOB}}_{\mathrm{s}, j}(t)=\mathrm{IOB}_{\mathrm{ss}, j}(t)+40 \mathrm{gCHO} / \mathrm{CR}_{j}(t)$.

- Medium meal $[35,65) \mathrm{gCHO} . \overline{\mathrm{IOB}}_{\mathrm{m}, j}(t)=\mathrm{IOB}_{\mathrm{ss}, j}(t)+55 \mathrm{gCHO} / \mathrm{CR}_{j}(t)$.

- Large meal $\geq 65 \mathrm{gCHO} . \overline{\mathrm{IOB}}_{1, j}(t)=\mathrm{IOB}_{\mathrm{ss}, j}(t)+70 \mathrm{gCHO} / \mathrm{CR}_{j}(t)$.

where $\mathrm{IOB}_{\mathrm{ss}, j}(t)$ is the steady state value of the model (12) corresponding to the basal insulin rate of each patient $i_{b, j}(t)$, and $X X \mathrm{gCHO} / \mathrm{CR}_{j}(t)$ is the insulin bolus corresponding to $x x$ grams of carbohydrates $(\mathrm{gCHO})$ by using the $\mathrm{CR}_{j}(t)$ factor of each patient at the meal time. When the system is not at a prandial period, the IOB limit is fixed as $\overline{\mathrm{IOB}}_{\mathrm{s}, j}(t)$, corresponding to a small meal. In this manner, the controller has an extra a degree of freedom in order to make adjustments to the basal infusion when necessary.

\section{Simulations}

All the in-silico experiments were carried out with the UVa/Padova Simulator, considering:

- a Dexom G4 Share ${ }^{\circledR}$ CGM;

- a generic CSII pump with a quantization of $0.1 \mathrm{U}$, and a maximum bolus of $25 \mathrm{U}$ (these characteristics are analogous to Roche Accu-Check Combo ${ }^{\circledR}$ pump);

- a glucose reference of $120 \mathrm{mg} / \mathrm{dl}$; and

- meal announcement.

Fig. 6 shows how the ARG algorithm works. It can be observed that the controller $\mathscr{K}_{1}$ is in charge of the insulin infusion most of the time, while the controller $\mathscr{K}_{2}$ only works during the meals. Once the controller $\mathscr{K}_{2}$ is selected, larger insulin boluses are delivered in order to avoid postprandial hyperglycemia. These boluses are modulated by the SAFE layer through the signal $\gamma$ in order to avoid the violation of the imposed constraint on the IOB. This way, excessive insulin stacking is avoided and the risk of hypoglycemia is reduced. From this analysis it can be seen that while the aggressive controller $\left(\mathscr{K}_{2}\right)$ diminishes hyperglycemia, the SAFE protection avoids hypoglycemia. Both systems work together in such a way to maintain the patient glycemia in the desirable $[70,180] \mathrm{mg} / \mathrm{dl}$ or acceptable $[70,250] \mathrm{mg} / \mathrm{dl} \mathrm{range}$.

It is also important to note that, as may be seen in figure 6 , the peak in the insulin infusion happens after the meal intake, opposed to the traditional therapy where the meal bolus is delivered minutes before eating. This delay is due to the feedback strategy. Here, the effect of the meal is not detected by the CGM until several minutes after the intake. This results in an inevitable increase in the levels of glycemia, that is later compensated by the aggressive LQG controller. Other control strategies have a hybrid structure, in which the patient administers a meal bolus and the controller is in charge of 


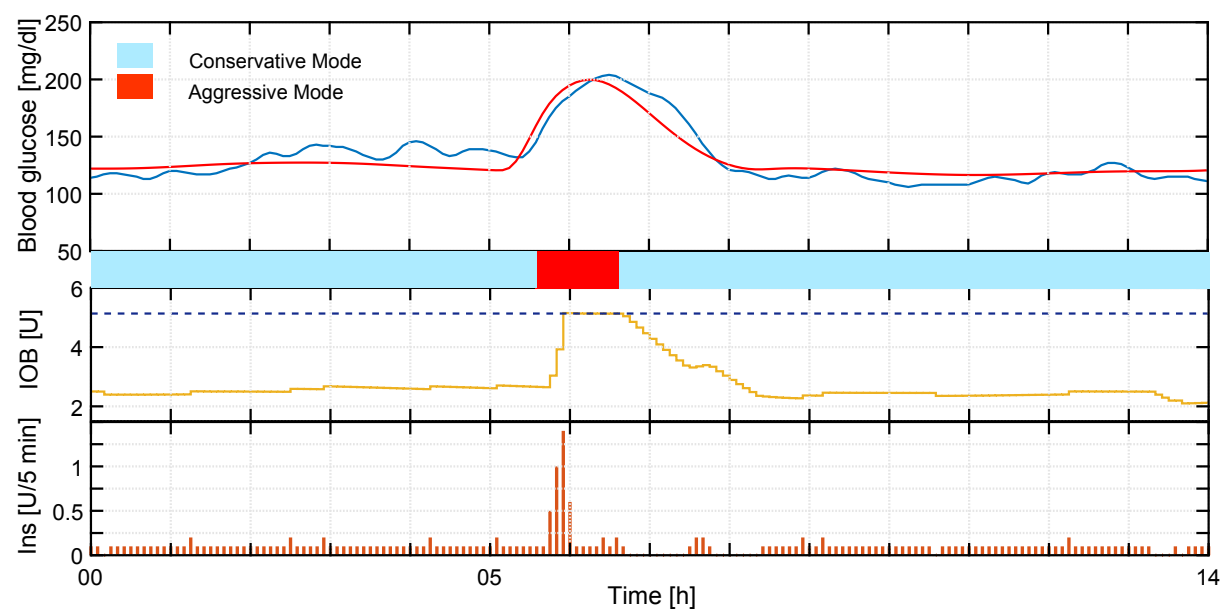

Figure 6. Example of the closed-loop response obtained when facing a $50 \mathrm{gCHO}$ meal of an in silico patient of the UVa/Padova Simulator. The meal intake happens 5 hours after the beginning of the simulation.
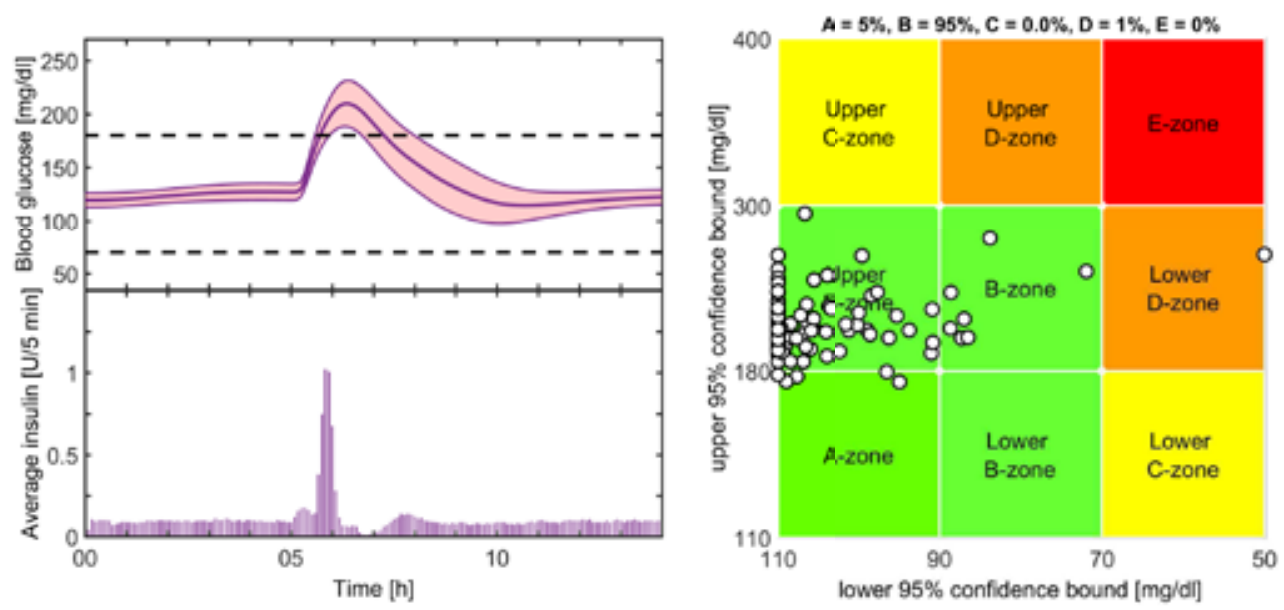

Figure 7. Mean closed-loop response for all the available adults in the UVa/Padova Simulator when facing a 50gCHO meal. Upper left: The solid line indicates the mean glucose and the shaded area is \pm 1 standard deviation. The dashed lines indicate the boundaries of the desirable range.Bottom left: Mean insulin infusion Right: CVGA plot.

regulating the basal delivery. This way, postprandial peaks could be reduced as the bolus would be infused at an earlier time than with the proposed strategy. Nonetheless, the patient would be responsible of carbohydrate counting, which is rarely exact in daily life and also imposes a task that goes against his/her quality of life.

Figure 7 shows the mean closed-loop response for all the available adults in the full version of the UVa/Padova Simulator, along with the Control Variability Grid Analysis (CVGA) plot. The different regions of the CVGA represent glycemic control as follows:

- A-zone: Accurate control.

- Lower/Upper B-zones: Benign deviations into hypo/hyperglycemia.

- B-zone: Benign control deviations.

- Upper/Lower C-zone: Over-correction of hypo/hyperglycemia.

- Lower/Upper D-zone: Failure to deal with hypo/hyperglycemia.

- E-zone: Erroneous control.

As it was previously mentioned, due to the greater autonomy the patients have, the upper B-zone has a larger density of points. Fortunately, this does not imply a greater risk to the patients health. Figure 7 also shows that there is one patient that fell into the lower D-zone (failure to deal with hypoglycemia). On one hand, it must be considered that not every in silico patient has parameters that make sense physiologically, given that the data base was generated for statistical ends. 
Table 1. Mean closed-loop results with the ARG algorithm, analyzing separately the entire simulation time (C) and the postprandial period (PP).

\begin{tabular}{|c|c|c|c|c|c|}
\hline & & $50 \mathrm{~g}$ meal & $25 \mathrm{~g}$ meal & $75 \mathrm{~g}$ meal & Two 50 g meals \\
\hline \multirow{2}{*}{ Mean glucose [mg/dl] } & $\mathbf{C}$ & 132 & 126 & 141 & 139 \\
\hline & $\mathbf{P P}$ & 160 & 135 & 188 & 155 \\
\hline \multirow{2}{*}{$\%$ time in $\left[\begin{array}{ll}70 & 180] \\
\mathrm{mg} / \mathrm{dl}\end{array}\right.$} & $\mathbf{C}$ & 91.8 & 99.1 & 84.8 & 86.2 \\
\hline & $\mathbf{P P}$ & 68.5 & 96.5 & 46.3 & 73.4 \\
\hline \multirow{2}{*}{$\%$ time $>250 \mathrm{mg} / \mathrm{dl}$} & $\mathbf{C}$ & 0.2 & 0.0 & 2.2 & 0.3 \\
\hline & $\mathbf{P P}$ & 0.8 & 0.0 & 9.7 & 0.6 \\
\hline \multirow{2}{*}{$\%$ time $>180 \mathrm{mg} / \mathrm{dl}$} & $\mathbf{C}$ & 8.1 & 0.7 & 15.1 & 13.6 \\
\hline & $\mathbf{P P}$ & 31.4 & 2.9 & 53.7 & 26.5 \\
\hline \multirow{2}{*}{$\%$ time $<70$ mg/dl } & $\mathbf{C}$ & 0.1 & 0.3 & 0.1 & 0.2 \\
\hline & $\mathbf{P P}$ & 0.1 & 0.5 & 0.0 & 0.1 \\
\hline LBGI & & 0.1 & 0.1 & 0.0 & 0.1 \\
\hline HBGI & & 1.7 & 0.8 & 3.2 & 2.7 \\
\hline
\end{tabular}

On the other hand, the proposed strategy allows facing these kind of singular cases where the controller action was either too conservative or too aggressive. To illustrate this, Fig. 8 shows how a slight adjustment in the IOB constraint for this particular patient allows avoiding postprandial hypoglycemia and solves this problem.

Figure 9 displays the results obtained when facing different amounts or consecutive carbohydrates. This figure shows the performance of the algorithm in these situations without considering the meal size (i.e. always using the IOB constraint defined for medium meals). Table 1 displays the meal results for all the considered cases. This table analyzes the glycemic levels obtained in both the entire simulation time and in the postprandial period (defined as 5 hours after meal intake). The risk of hypo and hyperglycemia indexes are also included. The scale for these indexes are defined according to [46]:

- Risk of hypoglycemia: LBGI $\leq 2.5$ (low); $2.5<$ LBGI $\leq 5$ (moderate); LBGI $>5$ (high).

- Risk of hyperglycemia: HBGI $\leq 4.5$ (low); $4.5<$ HBGI $\leq 9$ (moderate); HBGI $>9$ (high).

It can be observed that the ARG algorithm allows achieving minimal risk of hypo and hyperglycemia. Even though the results are satisfactory, they can be further improved with the addition of a meal classifier to help establish a more adequate IOB constraint. For example, when an IOB constraint for small meals $(<35 \mathrm{gCHO})$ is considered for the simulations with the $25 \mathrm{gCHO}$ meal, the mean time in hypoglycemia is reduced form $0.5 \%$ to $0.2 \%$, maintaining a mean time of $96.5 \%$ in the desirable range in the postprandial period. On the other hand, when an IOB constraint for large meals $(>65 \mathrm{mg} / \mathrm{dl})$ is considered with the $75 \mathrm{gCHO}$ meal, the mean time in the desirable range increases from $46.3 \%$ to $52.5 \%$ in the postprandial period, with a minimal increase in the mean time in hypoglycemia from 0 to $0.1 \%$.

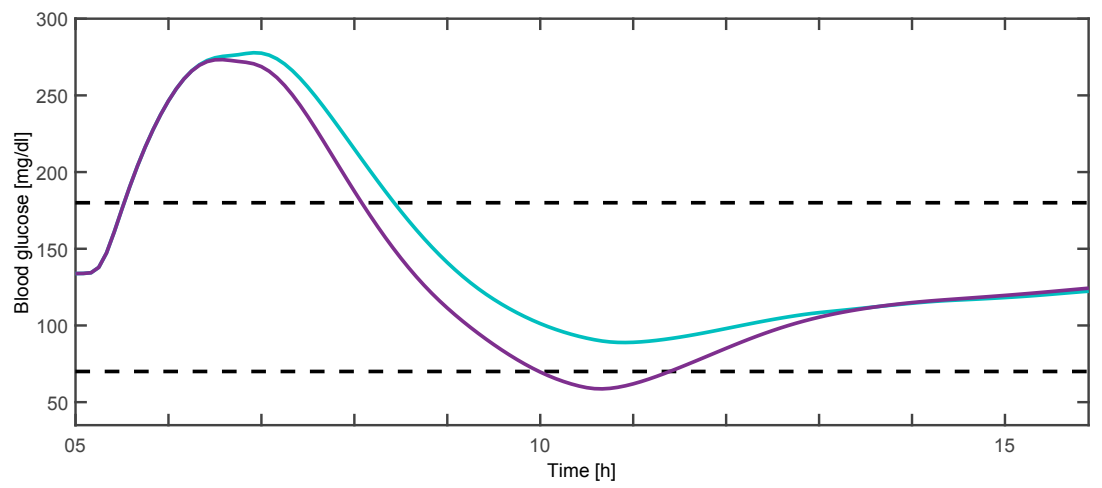

Figure 8. Closed-loop response for adult \#090 of the UVa/Padova Simulator with a standard IOB constraint (purple) and with an IOB constraint $30 \%$ lower than the standard (blue). The dashed lines indicate the boundaries of the desirable range. 

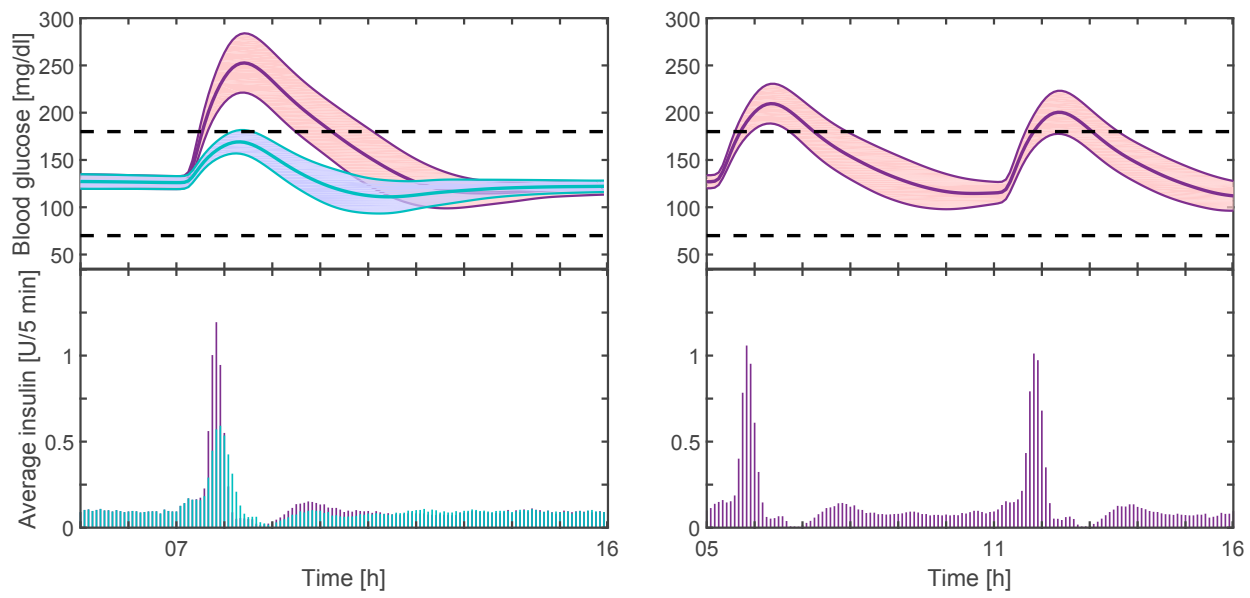

Figure 9. Mean closed-loop response for all the available adults in the UVa/Padova Simulator when facing one meal of $25 \mathrm{gCHO}$ (blue-left), $75 \mathrm{gCHO}$ (purple-left) and two meals of $50 \mathrm{gCHO}$ (right). Upper boxes: The solid line indicates the mean glucose and the shaded area is \pm 1 standard deviation. The dashed lines indicate the boundaries of the desirable range. Lower boxes: Mean insulin infusion.

\section{Clinical trials}

The first clinical trials with an AP in Latin America were carried out in two stages at the Hospital Italiano de Buenos Aires (HIBA). The first one in November 2016 with the algorithm of the University of Virginia that had been tested internationally in several occasions. The second trial was in June 2017 with the Automatic Regulation of Glucose (ARG) algorithm, fully developed in Argentina, a collaboration between researchers from the Instituto Tecnológico de Buenos Aires (ITBA), the Universidad Nacional de Quilmes (UNQ) and the Universidad Nacional de La Plata (UNLP). Both stages had the same numbers of patients (5), the same hardware, and followed the same clinical protocol. However, the main difference between both trials is that in the latter, the patients did not have to count CHO nor apply an insulin bolus. Here we will focus on this second clinical trial.

The selection of the 5 patients with T1DM that participated in the trials was made according to the clinical protocol, particularly the inclusion and exclusion criteria as indicated in NCT02994277 (www.clinicaltrials.gov).

\subsection{Hardware and software}

For the implementation of the AP the following devices were used in each patient:

- CGM Dexcom G4 Share ${ }^{\circledR}$;

- Accu-Check Combo ${ }^{\circledR}$ insulin pump from Roche; and

- a NEXUS-5 smartphone based on Android containing the Diabetes Assistant (DiAs) from the University of Virginia (UVa) [47].

The Diabetes Assistant (DiAs) is a software that includes several mobile applications and allows every 5 minutes the communication between the control algorithm, the CGM sensor (through Android Bluetooth Low Energy) and the insulin pump (through standard Bluetooth). Due to FDA regulations, to be accepted as a Class III medical device, the phone, navigator, Android Market, games, etc., were removed. The system also includes the SQLite database for the asynchronous data management for requests from the user.

The DiAs is a modular system where the control algorithm is contained. The ARG algorithm was programmed in the DiAs using Object-oriented programming on the Eclipse IDE for Java Developers version: Kepler Service Release 2, with the plugin Android Development Tools (ADT).

\subsection{Clinical procedures}

Patients were called to attend the HIBA nine days before the trial. That day, the protocol was explained in detail, the Informed Consent was signed, the inclusion/exclusion criteria were revised and a blood extraction was made for laboratory screening. These results, as well as a supervised glycaemic control were reviewed two days before the trial. That same day, the insulin pump and the CGM were connected to each patient, with a brief training in the use of both devices. The communication among these devices with the smartphone was verified and the systems remained in open loop (without the algorithm active in the smartphone) in order for the patients to perform their usual controls. They also had to perform 
eight daily capilar glycaemia measurements until the day of the trial, for comparison purposes. During these days, patients were allowed to carry on with their daily routines and to continue with their usual treatment. Meals were not restricted and patients were asked to record their daily food intakes.

The trial started at $1700 \mathrm{hs}$ on day 0 and ended the morning of day 2 . The loop was closed by activating the control algorithm in the smartphone and all patients had 5 meals during the 36 hs tests: two dinners, one lunch, one breakfast and one afternoon snack (see details below) with a continuous monitoring of their glycaemia and injected insulin values from the medical and researcher staff room. During these $36 \mathrm{hs}$, the ARG algorithm regulated the patients glycaemia using only CGM information and the meal announcement with CHO classification. Patients were allowed to walk freely around the hospital. If an hypoglycemia event occurred, rescue $\mathrm{CHO}$ were provided by the medical staff. If a patient presented glycemic values over $300 \mathrm{mg} / \mathrm{dl}$ for more than two hours, a manual bolus was injected following medical indications.

The menu coordinated by the nutritionist was as follows:

\section{- Breakfast and afternoon snack}

\begin{tabular}{|l|l|l|}
\hline Meal & Quantity $(\mathrm{g})$ & CHO $(\mathrm{g})$ \\
\hline Tea, coffee or mate & C/N & - \\
Wholegrain bread or 5 water crackers & $50(2$ units $)$ & 20 \\
Diet jam & $8(1$ jar $)$ & 8 \\
Spread cheese & 20 & - \\
\hline Total & & 28 \\
\hline
\end{tabular}

\section{- Dinner}

\begin{tabular}{|l|l|l|}
\hline Meal & Quantity $(\mathrm{g})$ & CHO $(\mathrm{g})$ \\
\hline Wheat pasta with natural filetto sauce & $50(\mathrm{raw})$ & 40 \\
Lean meat & 100 & - \\
Fressh fruit & 1 unit & 15 \\
\hline Total & & 55 \\
\hline
\end{tabular}

\section{- Lunch}

\begin{tabular}{|l|l|l|}
\hline Meal & Quantity $(\mathrm{g})$ & CHO $(\mathrm{g})$ \\
\hline Smashed potatoes with water $(285 \mathrm{cc})$ & $200(2$ units $)$ & 40 \\
Lean meat & 100 & - \\
Fresh fruit & 1 unit & 15 \\
\hline Total & & 55 \\
\hline
\end{tabular}

\subsection{Results}

Next, a brief description of the results is presented. For the Open Loop (OL) analysis is considered a time interval from 7 p.m. on day -2 up to 7 a.m. on day 0 . In the case of the Closed Loop (CL) period, the time interval is considered from 7 p.m. on day 0 up to 7 a.m. on day 2. The insulin pump of one of the patients had an occlusion during the first night in $\mathrm{CL}$, therefore, these hours were not considered in the analysis. The OL is used as a reference of their habitual glucose management and it should be noted that the patients did not follow the same diet during OL and CL. On table 2 it can be seen the statistical data obtained from the 36 hours of CL trial and the comparison with those obtained in OL. As can be observed, there is a significant improvement in the patient's glucose regulation when using the ARG algorithm. The null hypothesis at a level of significance of $5 \%(\rho=0.05)$, defined as the difference between the results obtained in OL and CL have zero mean, can be rejected in the percentage of time in euglycemic range [70, 180] mg/dl, being statistically significant $(\rho=0.0356)$.

Since it is the first clinical trial of the ARG algorithm, the 3 initial meals were used to make the necessary adjustments to the IOB maximum limit. For this reason, if the analysis of the results is concentrated in the last 15 hours of CL and it is 
Table 2. Comparison of the statistical data obtained from 36 hs in OL $v s$ CL, considering a confidence interval of $95 \%$.

\begin{tabular}{lllll}
\hline & \multicolumn{2}{c}{ OL } & \multicolumn{2}{c}{ CL } \\
\cline { 2 - 5 } & Mean & \multicolumn{1}{c}{ CI 95 \% } & Mean & CI 95\% \\
\hline \% time $[70,250] \mathrm{mg} / \mathrm{dl}$ & 82.9 & {$[67.3,98.6]$} & 88.6 & {$[82.4,94.7]$} \\
\% time $[70,180] \mathrm{mg} / \mathrm{dl}$ & 59.1 & {$[41.9,76.2]$} & 74.7 & {$[68.1,81.4]$} \\
$\%$ time $<70 \mathrm{mg} / \mathrm{dl}$ & 7.6 & {$[2.9,12.4]$} & 5.8 & {$[1.6,10.0]$} \\
$\%$ time $<50 \mathrm{mg} / \mathrm{dl}$ & 1.7 & {$[0.3,3.1]$} & 0.8 & {$[0.2,3.5]$} \\
LBGI & 2.8 & {$[1.83 .7]$} & 2.3 & {$[1.4,3.1]$} \\
HBGI & 7.2 & {$[3.4,11.0]$} & 4.9 & {$[2.9,6.9]$} \\
\hline
\end{tabular}

compared with the 15 hours of OL that involve the same period of the day, an even more significant control improvement is noticed, as it is shown in Table 3. A two-sampled t-test was carried out to determine if the results obtained in OL and CL are different at a level of significance of $5 \%(\rho=0.05)$. In this way, the null hypothesis was defined as "the difference between the results obtained in OL and CL has zero mean". For this trial, the null hypothesis can be rejected for the percentage time in euglycemic range $[70,180] \mathrm{mg} / \mathrm{dl}(\rho=0.0142)$, in $<70 \mathrm{mg} / \mathrm{dl}(\rho=0.049)$, LBGI index $(\mathrm{p}=0.0383)$ and HBGI index $(\rho=0.0469)$, these being statistically significant.

Table 3. Comparison of the statistical data obtained from first $15 \mathrm{hs}$ in $\mathrm{OL}$ and the last $15 \mathrm{hs}$ in CL, considering a confidence interval of $95 \%$.

\begin{tabular}{lllll}
\hline & \multicolumn{2}{c}{ OL } & \multicolumn{2}{c}{ CL } \\
\cline { 2 - 5 } & Mean & \multicolumn{1}{c}{ CI 95 \% } & Mean & CI 95\% \\
\hline \% time $[70,250] \mathrm{mg} / \mathrm{dl}$ & 73.5 & {$[49.8,97.2]$} & 94.7 & {$[83.8,98.4]$} \\
\% time $[70,180] \mathrm{mg} / \mathrm{dl}$ & 49.8 & {$[24.5,75.1]$} & 82.6 & {$[69.9,95.2]$} \\
$\%$ time $<70 \mathrm{mg} / \mathrm{dl}$ & 13.6 & {$[4.4,22.7]$} & 4.1 & {$[0.8,18.0]$} \\
$\%$ time $<50 \mathrm{mg} / \mathrm{dl}$ & 5.4 & {$[1.6,16.4]$} & 0.2 & {$[0.0,3.5]$} \\
LBGI & 4.2 & {$[2.16 .2]$} & 1.8 & {$[0.3,3.3]$} \\
HBGI & 8.7 & {$[2.9,14.5]$} & 2.8 & {$[0.1,5.5]$} \\
\hline
\end{tabular}

It is important to remark that taking into account the night period (from 23 p.m. until 7 a.m.) the ARG algorithm presents a notorious improvement in comparison with the OL treatment. In Fig. 10 it is highlighted the comparison of the glucose excursion obtained during the second night in OL and in CL (time lapse without meals). In Table 4 the statistical data is presented regarding this period. Again, an improvement in percentage of time in euglycemia $(\rho=0.0351)$ and HBGI index $(\rho=0.0309)$ was obtained.

Table 4. Comparison of the statistical data obtained from the last nights in OL $v s$ CL, considering a confidence interval of $95 \%$

\begin{tabular}{lllll}
\hline & \multicolumn{2}{c}{ OL } & \multicolumn{2}{l}{ CL } \\
\cline { 2 - 5 } & Mean & CI 95 \% & Mean & CI 95\% \\
\hline \% time $[70,250] \mathrm{mg} / \mathrm{dl}$ & 78.1 & {$[29.1,96.9]$} & 95 & {$[66.9,99.4]$} \\
$\%$ time $[70,180] \mathrm{mg} / \mathrm{dl}$ & 50.3 & {$[23.2,77.4]$} & 87.7 & {$[76.5,99.0]$} \\
$\%$ time $<70 \mathrm{mg} / \mathrm{dl}$ & 3.6 & {$[0.3,29.5]$} & 5 & {$[0.6,33.1]$} \\
$\%$ time $<50 \mathrm{mg} / \mathrm{dl}$ & 0 & {$[0.0,0.0]$} & 0 & {$[0.0,0.0]$} \\
LBGI & 2.0 & {$[0.6,3.4]$} & 1.5 & {$[0.4,4.1]$} \\
HBGI & 9.8 & {$[2.8,16.8]$} & 1.9 & {$[0.4,5.7]$} \\
\hline
\end{tabular}

\section{Conclusions}

In this paper a brief review of the artificial pancreas project in Argentina was presented alongside with a novel control strategy for glycemic regulation: the ARG algorithm. It consists of a two-degree-of-freedom control structure that includes a switched LQG inner controller together with an outer sliding mode safety loop, the Safety Auxiliary Feedback Element (SAFE) mechanism, for IOB constraints. The switched LQG control strategy is a simplified version of the one in [35]. The switched nature of the inner controller enables different tunings for dealing with prandial and fasting periods and can be extended to other situations, e.g., physical activity. New and more complex scenarios could be potentially 


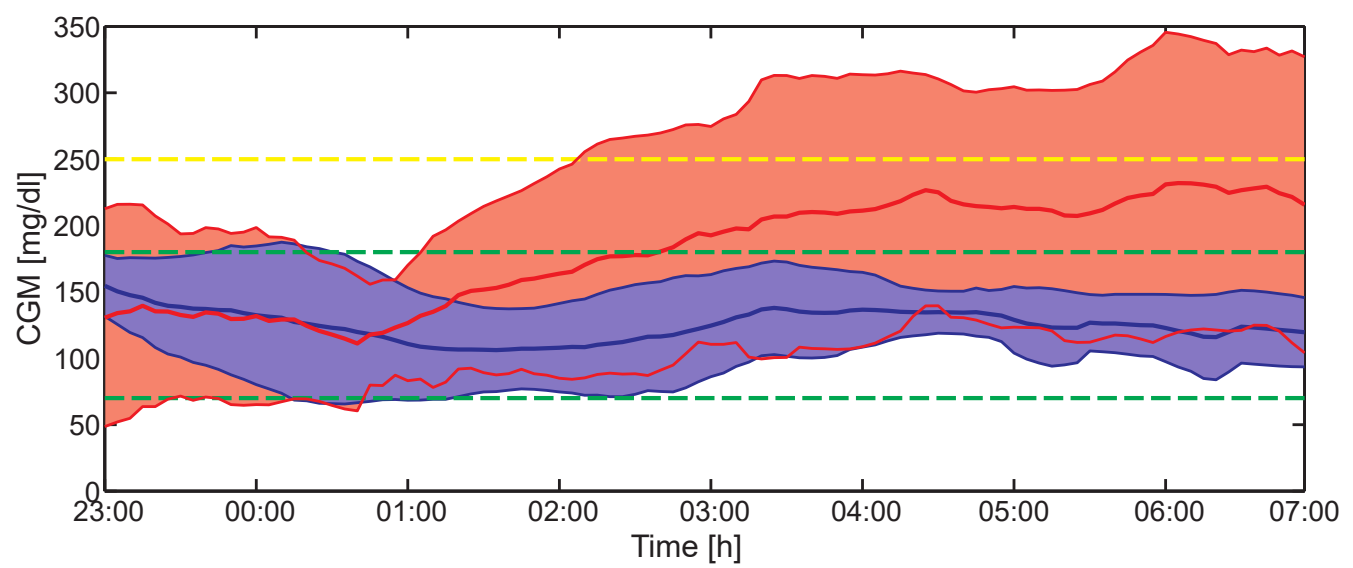

Figure 10. Mean glycemic excursion of all 5 patients in OL (red) and in CL (blue) during night time. The solid line indicates mean and the grey area \pm 1 standard deviation.

addressed by redesigning the switching policy and/or the IOB constraints. The SAFE layer quickly adapts the controller gain to automatically obtain insulin spikes like the open-loop boluses. Promising results were obtained both in silico and later in vivo during the first clinical trials in Latin America.

\section{Acknowledgements}

Access to the complete version of the University of Virginia/Padova metabolic simulator was provided by an agreement with Prof. C. Cobelli (University of Padova) and Prof. B. P. Kovatchev (University of Virginia) for research purposes. The authors would like to acknowledge Dr. Daniel Cherñavvsky for his very generous collaboration. We would also like to thank the physicians of the Hospital Italiano Ventura Simonovich, Paula Scibona, Cintia Rodriguez, Javier Giunta and Valeria Beruto coordinated by Dr. Luis Grosembacher and Dr. Waldo Belloso without whom this clinical trial could not have been possible. Additionally, we express our gratitude to the nutritionist Marianela Stasi who worked with us in the elaboration of the menu used. Finally, we want to highlight the collaboration with Dexcom, the generous donation by Roche and the funding of the Cellex (Spain) and Nuria (Argentina) Foundations.

\section{References}

[1] A. Chait and K. E. Bornfeldt. Diabetes and atherosclerosis: Is there a role for hyperglycemia? J. Lipid Res., 50:S335-S339, Apr. 2009.

[2] The Diabetes Control and Complications Trial Research Group. Hypoglycemia in the diabetes control and complications trial. Diabetes, 46(2):271-286, 1997.

${ }^{[3]}$ E. Renard. Insulin delivery route for the artificial pancreas: Subcutaneous, intraperitoneal, or intravenous? Pros and cons. J. Diabetes Sci. Technol., 2(4):735-738, July 2008.

[4] B. W. Bequette. Challenges and recent progress in the development of a closed-loop artificial pancreas. Annu. Rev. Control, 36(2):255-266, Dec 2012.

[5] G. M. Steil, A. E. Panteleon, and K. Rebrin. Closed-loop insulin delivery-the path to physiological glucose control. Adv. Drug Deliv. Rev., 56(2):125-144, Feb 2004.

[6] J Walsh, R. Roberts, and L. Heinemann. Confusion regarding duration of insulin action: A potential source for major insulin dose errors by bolus calculators. J. Diabetes Sci. Technol., 8(1):170-178, Jan 2014.

[7] B. P. Kovatchev, M. Breton, C. Dalla-Man, and C. Cobelli. In silico model and computer simulation environment approximating the human glucose/insulin utilization. Food and Drug Administration Master File MAF 1521, 2008.

${ }^{[8]}$ B. P. Kovatchev, M. Breton, C. Dalla Man, and C. Cobelli. In silico preclinical trials: A proof of concept in closed-loop control of type 1 diabetes. J. Diabetes Sci. Technol., 3(1):44-55, Jan. 2009.

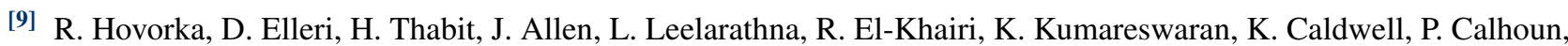
C. Kollman, H. Murphy, C. Acerini, M. Wilinska, M. Nodale, and D. Dunger. Overnight closed-loop insulin delivery in young people with type 1 diabetes: A free-living, randomized clinical trial. Diabetes Care, 37(5):1204-1211, 2014.

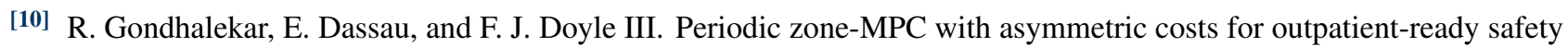
of an artificial pancreas to treat type 1 diabetes. Automatica, 71(9):237-246, Sept. 2016. 
[11] Moshe Phillip, Tadej Battelino, Eran Atlas, Olga Kordonouri, Natasa Bratina, Shahar Miller, Torben Biester, Magdalena Stefanija, Ido Muller, Revital Nimri, and Thomas Danne. Nocturnal glucose control with an artificial pancreas at a diabetes camp. N. Engl. J. Med., 368(9):824-833, Feb. 2013.

[12] Martin de Bock, Anirban Roy, Matthew Cooper, Julie Dart, Carolyn Berthold, Adam Retterath, Kate Freeman, Benyamin Grosman, Natalie Kurtz, Fran Kaufman, Timothy Jones, and Elizabeth Davis. Feasibility of outpatient 24-hour closed-loop insulin delivery. Diabetes Care, 38(11):e186-e187, Nov. 2015.

[13] T.T. Ly, A Roy, B Grosman, J Shin, A Campbell, S Monirabbasi, B Liang, R von Eyben, S Shanmugham, P Clinton, and B. A. Buckingham. Day and night closed-loop control using the integrated Medtronic hybrid closed-loop system in type 1 diabetes at diabetes camp. Diabetes Care, 38(7):1205-1211, Jul 2015.

[14] L. Bally, H. Thabit, H. Kojzar, J. K. Mader, J. Qerimi-Hyseni, S. Hartnell, M. Tauschmann, J. M. Allen, M. E. Wilinska, T. R. Pieber, M. L. Evans, and R. Hovorka. Day-and-night glycaemic control with closed-loop insulin delivery versus conventional insulin pump therapy in free-living adults with well controlled type 1 diabetes: An open-label, randomised, crossover study. Lancet Diabetes Endocrinol., 5(4):261-270, Apr 2017.

[15] Boris P. Kovatchev, Peiyao Cheng, Stacey M. Anderson, Jordan E. Pinsker, Federico Boscari, Bruce A. Buckingham, Francis J. Doyle III, Korey K. Hood, Sue A. Brown, Marc D. Breton, Daniel Chernavvsky, Wendy C. Bevier, Paige K. Bradley, Daniela Bruttomesso, Simone Del Favero, Roberta Calore, Claudio Cobelli, Angelo Avogaro, Trang T. Ly, Satya Shanmugham, Eyal Dassau, Craig Kollman, John W. Lum, and Roy W. Beck. Feasibility of long-term closedloop control: A multicenter 6-month trial of 24/7 automated insulin delivery. Diabetes Technol. Ther., 19(1):18-24, Jan 2017.

[16] G. P. Forlenza, S. Deshpande, T. T. Ly, D. P. Howsmon, F. Cameron, N. Baysal, E. Mauritzen, T. Marcal, L. Towers, B. W. Bequette, L. M. Huyett, J. E. Pinsker, R. Gondhalekar, F. J. Doyle III, D. M. Maahs, B. A. Buckingham, and E. Dassau. Application of zone model predictive control artificial pancreas during extended use of infusion set and sensor: A randomized crossover-controlled home-use trial. Diabetes Care, 40(8):1096-1102, Aug 2017.

[17] Mirko Messori, Jort Kropff, Simone Del Favero, Jerome Place, Roberto Visentin, Roberta Calore, Chiara Toffanin, Federico Di Palma, Giordano Lanzola, Anne Farret, Federico Boscari, Silvia Galasso, Angelo Avogaro, Patrick Keith-Hynes, Boris P. Kovatchev, Daniela Bruttomesso, Lalo Magni, J Hans DeVries, Eric Renard, Claudio Cobelli, and for the AP@home consortium. Individually adaptive artificial pancreas in subjects with type 1 diabetes: A one-month proof-of-concept trial in free-living conditions. Diabetes Technol. Ther., 19(10):560-571, Oct 2017.

[18] A Haidar, V Messier, L Legault, M Ladouceur, and R. Rabasa-Lhoret. Outpatient 60-hour day-and-night glucose control with dual-hormone artificial pancreas, single-hormone artificial pancreas, or sensor-augmented pump therapy in adults with type 1 diabetes: An open-label, randomised, crossover, controlled trial. Diabetes Obes. Metab., 19(5):713-720, May 2017.

[19] F. H. El-Khatib, C Balliro, M. A. Hillard, K. L. Magyar, L Ekhlaspour, M Sinha, D Mondesir, A Esmaeili, C Hartigan, M. J. Thompson, S Malkani, J. P. Lock, D. M. Harlan, P. Clinton, E Frank, D. M. Wilson, D DeSalvo, L Norlander, T Ly, B. A. Buckingham, J Diner, M Dezube, L. A. Young, A Goley, M. S. Kirkman, J. B. Buse, H. Zheng, R. R. Selagamsetty, E. R. Damiano, and S. J. Russell. Home use of a bihormonal bionic pancreas versus insulin pump therapy in adults with type 1 diabetes: A multicentre randomised crossover trial. Lancet, 389(10067):369-380, Jan 2017.

[20] Stuart A. Weinzimer, Garry M. Steil, Karena L. Swan, Jim Dziura, Natalie Kurtz, and William V. Tamborlane. Fully automated closed-loop insulin delivery versus semiautomated hybrid control in pediatric patients with type 1 diabetes using an artificial pancreas. Diabetes Care, 31(5):934-939, May 2008.

[21] A. S. Brazeau, H Mircescu, K Desjardins, C Leroux, I Strychar, J. M. Ekoé, and R. Rabasa-Lhoret. Carbohydrate counting accuracy and blood glucose variability in adults with type 1 diabetes. Diabetes Res. Clin. Pract., 99(1):19-23, Jan 2013.

[22] V Gingras, R Rabasa-Lhoret, V Messier, M Ladouceur, L Legault, and A. Haidar. Efficacy of dual-hormone artificial pancreas to alleviate the carbohydrate-counting burden of type 1 diabetes: A randomized crossover trial. Diabetes Metab., 42(1):47-54, Feb 2016.

[23] V Gingras, A Haidar, V Messier, L Legault, M Ladouceur, and R Rabasa-Lhoret. A simplified semiquantitative meal bolus strategy combined with single- and dual-hormone closed-loop delivery in patients with type 1 diabetes: A pilot study. Diabetes Technol. Ther., 18(8):464-471, Aug 2016.

[24] G. M. Steil, K Rebrin, C Darwin, F Hariri, and M. F. Saad. Feasibility of automating insulin delivery for the treatment of type 1 diabetes. Diabetes, 55(12):3344-3350, Dec 2006.

[25] E. Dassau, H. Zisser, R. Harvey, M. Percival, B. Grosman, W. Bevier, E. Atlas, S. Miller, R. Nimri, L. Jovanovič, and F. J. Doyle III. Clinical evaluation of a personalized artificial pancreas. Diabetes Care, 36(4):801-809, Apr. 2013. 
[26] M Reddy, P Herrero, M. E. Sharkawy, P. Pesl, N Jugnee, D Pavitt, I. F. Godsland, G Alberti, C Toumazou, D. G. Johnston, P Georgiou, and N. S. Oliver. Metabolic control with the bio-inspired artificial pancreas in adults with type 1 diabetes: A 24-hour randomized controlled crossover study. J. Diabetes Sci. Technol., 10(2):405-413, Nov 2015.

[27] H Blauw, A. C. van Bon, R Koops, J. H. DeVries, and on behalf of the PCDIAB consortium. Performance and safety of an integrated bihormonal artificial pancreas for fully automated glucose control at home. Diabetes Obes. Metab., 18(7):671-677, Jul 2016.

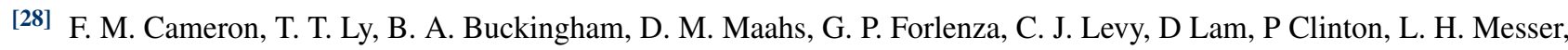
E Westfall, C Levister, Y. Y. Xie, N. Baysal, D Howsmon, S. D. Patek, and B. W. Bequette. Closed-loop control without meal announcement in type 1 diabetes. Diabetes Technol. Ther., 19(9):527-532, Sep 2017.

[29] K. Turksoy, I. Hajizadeh, S. Samadi, J. Feng, M. Sevil, M. Park, L. Quinn, E. Littlejohn, and A. Cinar. Real-time insulin bolusing for unannounced meals with artificial pancreas. Control Eng. Pract., 59(Supplement C):159-164, Feb 2017.

[30] F. M. Cameron, G. Niemeyer, and B. W. Bequette. Extended multiple model prediction with application to blood glucose regulation. J. Process Contr., 22(8):1422-1432, Sep 2012.

[31] Ali Cinar. Special issue on artificial pancreas systems. IEEE Control Systems Magazine, 38(1), Feb. 2018.

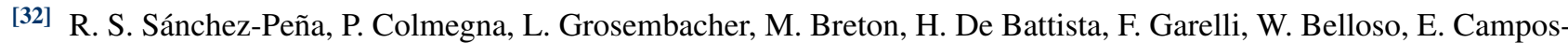
Náñez, V. Simonovich, V. Beruto, P. Scibona, and D. Cherñavvsky. Artificial Pancreas: First clinical trials in Argentina. In 20th IFAC World Congress, pages 7997-8002, Toulouse, France, 2017.

[33] P.Colmegna, F. Garelli, H. De Battista, and Ricardo Sánchez-Peña. Automatic regulatory control in type 1 diabetes without carbohydrate counting. Control Engineering Practice, 74:22-32, 2018.

[34] P. Colmegna, R. S. Sánchez-Peña, R. Gondhalekar, E. Dassau, and F. J. Doyle III. Reducing risks in type 1 diabetes using $\mathscr{H}_{\infty}$ control. IEEE Trans. Biomed. Eng., 61(12):2939-2947, Dec. 2014.

[35] P. Colmegna, R. S. Sánchez-Peña, R. Gondhalekar, E. Dassau, and F.J. Doyle III. Switched LPV glucose control in type 1 diabetes. IEEE Trans. Biomed. Eng., 63(6):1192-1200, June 2016.

[36] P. Colmegna, R. S. Sánchez-Peña, R. Gondhalekar, E. Dassau, and F. J. Doyle III. Reducing glucose variability due to meals and postprandial exercise in T1DM using switched LPV control: In silico studies. J. Diabetes Sci. Technol., 10(3):744-753, May 2016.

[37] P. Colmegna, R. Sánchez-Peña, and R. Gondhalekar. Linear parameter-varying model to design control laws for an artificial pancreas. Biomed. Signal Process Control, 40:204-213, Feb. 2018.

[38] P. Colmegna, R. Sánchez-Peña, and R. Gondhalekar. Control-oriented linear parameter-varying model for glucose control in type 1 diabetes. In IEEE Multi-Conference on Systems and Control, pages 410-415, Buenos Aires, Argentina, 2016.

[39] Klaske van Heusden, Eyal Dassau, Howard C. Zisser, Dale E. Seborg, and Francis J. Doyle III. Control-relevant models for glucose control using a priori patient characteristics. IEEE Trans. Biomed. Eng., 59(7):1839-1849, July 2012.

[40] J. P. Hespanha and A. S. Morse. Switching between stabilizing controllers. Automatica, 38(11):1905-1917, Nov. 2002.

[41] F. Garelli, R. Mantz, and H. De Battista. Advanced Control for Constrained Processes and Systems. IET Institution of Engineering and Technology, London, United Kingdom, 2011.

[42] A. Revert, F. Garelli, J. Picó, H. De Battista, P. Rossetti, J. Vehi, and J. Bondía. Safety auxiliary feedback element for the artificial pancreas in type 1 diabetes. IEEE Trans. Biomed. Eng., 60(8):2113-2122, Aug. 2013.

[43] M. E. Willinska, L. J. Chassin, H. C. Schaller, L. Schaupp, T. R. Pieber, and R. Hovorka. Insulin kinetics in type 1 diabetes: Continuous and bolus delivery of rapid acting insulin. IEEE Trans. Biomed. Eng., 52(1):3-12, Jan. 2005.

[44] J. Walsh and R. Roberts. Pumping Insulin. Torrey Pines Press, San Diego, CA, 4 edition, 2006.

[45] F. León-Vargas, F. Garelli, H. De Battista, and J. Vehi. Postprandial response improvement via safety layer in closed-loop blood glucose controllers. Biomed. Signal Process Control, 16:80-87, Feb. 2015.

[46] B. Kovatchev, G. Umpierrez, A. DiGenio, R. Zhou, and S. E. Inzucchi. Sensitivity of traditional and risk-based glycemic variability measures to the effect of glucose-lowering treatment in type 2 diabetes mellitus. J. Diabetes Science and Technology, 9(6):1227-1235, Nov. 2015.

[47] P. Keith-Hynes, B. Mize, A. Robert, and J. Place. The diabetes assistant: A smartphone-based system for real-time control of blood glucose. Electronics, 3(4):609-623, Nov. 2014. 


\section{Bios}

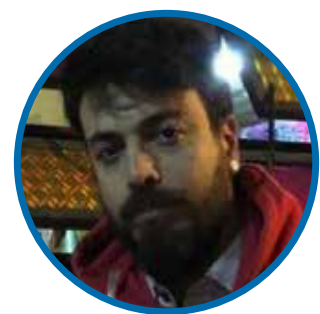

\section{Nicolás Rosales}

Nicolás Rosales was born in Trelew, Argentina, in 1990. He obtained a B.S.E.E. degree at the National University of La Plata (UNLP), La Plata, Argentina, in 2015, where he is currently working towards his Ph.D. degree at the Laboratory of Industrial Electronics, Control and Instrumentation (LEICI). His main research interests are in artificial pancreas systems. He specializes in both open- and closed-loop glucose control strategies.

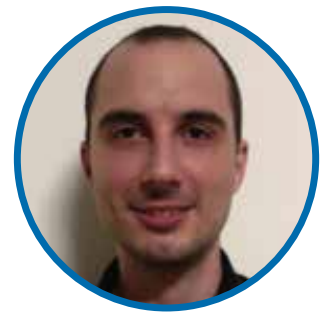

\section{Patricio Colmegna}

Patricio Colmegna obtained an Engineering degree at the University of Quilmes (UNQ), in 2010, and a doctoral degree in Engineering at Buenos Aires Institute of Technology (ITBA), in 2014. His doctoral research focused on applying optimal, robust and switched control algorithms to an artificial pancreas (AP) that aimed to not only mitigate glucose excursions, but also reduce patient burden. In 2017, he was named Research Assistant at the National Research Council (CONICET), and was part of the team that performed the first clinical AP trial in Latin America. Dr. Colmegna joined the Center For Diabetes Technology, University of Virginia, in early 2018, and is currently working on the development of a next-generation simulation facility for diabetes. This effort involves the design of new and more computationally efficient platforms for multi-model, multi-disease modeling and simulation.

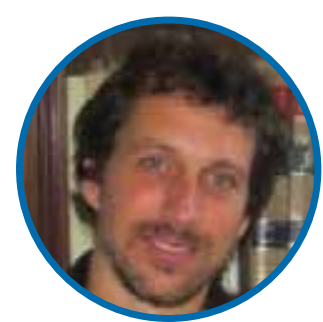

\section{Fabricio Garelli}

Fabricio Garelli is currently Full Professor at the National University of La Plata (UNLP) and Official Member of the National Research Council (CONICET). He is the author of an awarded Ph.D. thesis, an IET book, and more than a hundred journal or conference papers. His research work focuses on constrained automatic control and estimation via sliding mode techniques, with application to industrial processes/bioprocesses, robotics and biomedical engineering (artificial pancreas).

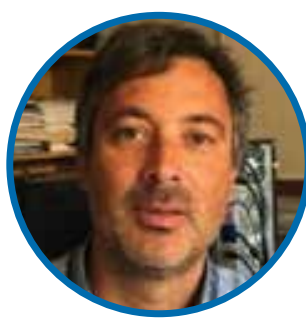

\section{Hernán De Battista}

Hernán De Battista was born in La Plata, Argentina, in 1968. He obtained his M.Sc. in Engineering with highest honors in 1994, followed by a PhD in 2000, both at the National University of La Plata, Argentina. Currently, he is Full Professor at the School of Engineering, National University of La Plata, and Principal Researcher of the National Research Council (CONICET), Argentina. His main research interests are in non-linear control and its applications to renewable energies and biological systems. He has coauthored two books and 65 journal articles. He received the E. Galloni award from the Argentine Academy of Exact, Physical and Natural Sciences in 2002 and the S. Gershanik award from the Buenos Aires Academy of Engineering in 2006.

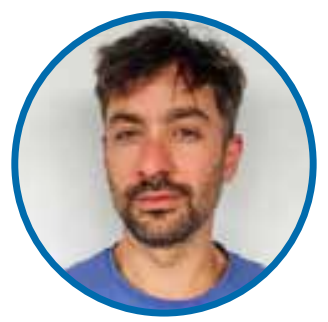

\section{Demián García-Violini}

Demián García-Violini obtained a B.Sc. degree in Automation and Control Engineering at the National University of Quilmes (UNQ), Buenos Aires, Argentina, in 2010, and a doctoral degree in Engineering at Buenos Aires Institute of Technology (ITBA), in 2015. He is currently a Postdoctoral Researcher at the Centre of Ocean Energy Research, National University of Ireland Maynooth, and he is also working as a Teaching Assistant in Control Systems courses at UNQ. His research interests include modeling, identification, and robust control for diverse problems, such as control of wave energy converters, type 1 diabetes mellitus, and synchronization between different cerebral structures.

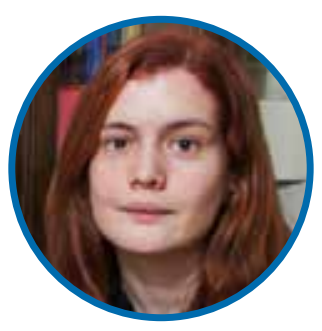

\section{Marcela Moscoso- Vázquez}

Marcela Moscoso-Vázquez obtained a B.Sc. degree and a Master degree, both in Chemical Engineering, at the National University of Colombia, Medellín, in 2011 and 2014, respectively, supported by the Outstanding Graduate Student Scholarship. She also obtained a Doctoral degree in Engineering at Buenos Aires Institute of Technology (ITBA), Argentina, in 2019, supported by a CONICET doctoral scholarship. 
She is currently a Postdoctoral Researcher at CONICET in Argentina, and is a Teaching Assistant at the Chemical Process Control course at ITBA. Her research interests include modeling and analysis of circadian rhythms, control-oriented modeling and identification for robust control of type 1 diabetes mellitus, and model-based control of chemical processes.

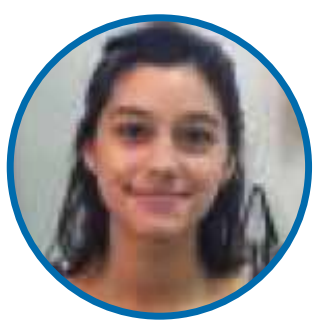

\section{Emilia Fushimi}

Emilia Fushimi was born in Buenos Aires, Argentina, in 1993. She obtained a B.S.E.E. degree at the National University of La Plata (UNLP), La Plata, Argentina, in 2016, where she is currently working towards her Ph.D. degree at the Laboratory of Industrial Electronics, Control and Instrumentation. She is also a Graduate Student Assistant at the Department of Electrical Engineering, UNLP. Her main research interests are focused on the artificial pancreas.

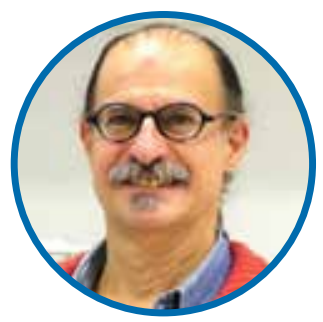

\section{Ricardo S. Sánchez-} Peña

Ricardo S. Sánchez-Peña has an EE degree from the University of Buenos Aires (UBA) and a M.S. and Ph.D. from the California Institute of Technology. Since 1977, he has worked at CITEFA, CNEA, CNIE and CONAE in Argentina. He has collaborated with NASA and the German and Brazilian space agencies. He has been a Professor at UBA and UPC (Spain) as an ICREA researcher. He has been visiting professor and researcher at various universities, as well as a consultant for companies in topics related to aerospace and energy applications in the USA and the EU. He has received awards from IEEE, NASA and ANCEFN. Presently he is Director of the Research \& PhD Department, Buenos Aires Institute of Technology (ITBA), Investigador Superior of the National Research Council (CONICET), and he leads the Artificial Pancreas project in Argentina. Corresponding author. Email: rsanchez@itba.edu.ar. 